\title{
REGULACIÓN CONSTITUCIONAL DE LOS DERECHOS FUNDAMENTALES Y OBJECIÓN DE CONCIENCIA SOBREVENIDA*
}

\section{Introducción}

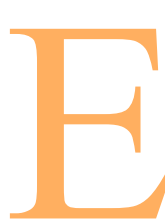

1 análisis de cómo están configurados los derechos fundamentales en la Constitución es, a primera vista, competencia de los especialistas en Derecho constitucional más que de los filósofos del Derecho. Sin embargo no es difícil darse cuenta de que en la interpretación de los derechos fundamentales surgen problemas filosóficos (empezando por el mismo sentido de la interpretación), y que, por tanto, la filosofía del Derecho es relevante también para determinar qué, cómo e incluso cuáles son los derechos fundamentales, y no sólo por qué lo son. Con este pequeño trabajo intentaré ratificar la afirmación anterior, pues sin ser de ningún modo un especialista en la Constitución pretendo aportar algunas ideas sobre la correcta interpretación constitucional de los derechos fundamentales, inspirado por unas cuantas nociones iusfilosóficas. Para ilustrar mi planteamiento sobre los derechos constitucionales he escogido como caso de estudio la objeción de conciencia sobrevenida, que aquí será tratada como un objeto de interés de la Teoría del Derecho más que como un problema moral.

La objeción [de conciencia] sobrevenida es la objeción de conciencia al servicio militar que se manifiesta cuando el objetor ya ha ingresado en filas. Es, por tanto, la actitud o la conducta de quien por motivos de conciencia se niega a continuar participando en un ejército al que pertenece por obligación. Como es sabido, la Ley 22/1988, de 6 de julio, reguladora de la objeción de conciencia y de la prestación social sustitutoria, no reconoce a este tipo de objeción como eximente del servicio militar. Su artículo 1.3 dispone que la solicitud de objeción puede ejercerse «hasta la fecha señalada por el Ministerio de Defensa para su incorporación al servicio militar, o una vez finalizado el mismo, mientras se permanezca en la situación de reserva».

* Este trabajo es una versión retocada de la comunicación «La regulación constitucional de la objeción de conciencia sobrevenida», presentada en las XVII Jornadas de Filosofía Jurídica y Social (Toledo, 19 y 20 de marzo de 1997). 
De hecho, hoy por hoy en España la única forma de objeción de conciencia al servicio militar que no está jurídicamente admitida es la sobrevenida. Esta situación ha sido convalidada por el Tribunal Constitucional en una polémica Sentencia: STC 161/1987, de 27 de octubre, que se ocupó de un precepto similar en la Ley 48/1984, de 26 de diciembre, que regulaba la objeción de conciencia y la prestación social sustitutoria antes de ser derogada por la Ley 22/1988 citada. $^{1}$

La STC 161/1987 resolvió las cuestiones de inconstitucionalidad relativas a la Ley 48/1984 promovidas por la Sección Primera de la Sala de lo Contencioso-Administrativo de la Audiencia Nacional. Según la Sentencia la exclusión legal cuestionada respeta el contenido esencial del derecho a la objeción de conciencia y «resulta justificable en atención a la organización interna del servicio militar obligatorio y a la prestación de un deber constitucional cuya dimensión colectiva podría resultar perturbada por el ejercicio individual del derecho durante el período de incorporación a filas...» (fundamento jurídico 5). El TC argumentó que «el legislador ha de armonizar en la forma que estime más conveniente el derecho individual del objetor con la salvaguardia del objeto o fines constitucionalmente reconocidos (la defensa de España y las Fuerzas Armadas a su servicio) [...]», sin incurrir en arbitrariedad y respetando el contenido esencial del derecho a la objeción de conciencia $\left(\mathrm{FJ}^{\circ}\right)$. A juicio del Tribunal la exclusión legal respeta el contenido esencial del derecho, pues se trata de una restricción proporcionada en relación con los demás intereses constitucionalmente protegibles, los cuales el legislador está forzado a ponderar con el fin de regular el derecho «con las debidas garantías» $\left(\mathrm{FJ}^{\circ}\right)$. En efecto, según el Tribunal «es necesario ponderar si el ejercicio del derecho a la objeción del artículo 30.2 durante la fase de permanencia en filas resulta perturbador para la seguridad de la estructura interna de las Fuerzas Armadas, que deben estar en todo momento en condiciones de cumplir sus cometidos militares»; y no es excesivo o carente de justificación que el legislador haya entendido que así ocurre (ibídem).

Pues bien, en lo que sigue voy a defender un enfoque doctrinal de los derechos fundamentales que no sólo prefiere, sino que implica, el tratamiento de la objeción sobrevenida según el cual su prohibición es inconstitucional en España. Sirva de modelo de este tratamiento el voto particular formulado por el Magistrado don Miguel Rodríguez-Piñero a la citada STC 161/1987. En dicho voto se lee:

${ }^{1}$ El art. 1.3 de la Ley 48/1984 disponía que la solicitud de objeción podía ejercerse «hasta el momento en que se produzca la incorporación militar en filas $\mathrm{y}$, una vez finalizada ésta, mientras se permanezca en situación de reserva». 
«A mi juicio lo que ha de analizarse no es la razonabilidad de la medida, sino exclusivamente su compatibilidad con el contenido esencial del derecho a la objeción de conciencia. Derecho que garantiza al ciudadano eximirse del servicio militar cuando ello está en contradicción con los dictados íntimos de su conciencia. El hecho de que la objeción de conciencia sea «sobrevenida», es decir surja con tal objeción en el momento de la prestación del servicio en filas, no es un obstáculo para el surgimiento de tal derecho. La constitución habla genéricamente de "exención del servicio militar obligatorio", sin que puedan establecerse distinciones al respecto...».

\section{Contenido esencial del Derecho y reglas constitucionales}

La noción de «contenido esencial» de los derechos fundamentales es lo suficientemente polémica como para no poder abordarla aquí en profundidad, pero es indudable que debemos tenerla en cuenta porque es la clave de nuestro problema. En efecto, el juicio sobre la licitud constitucional de prohibir la objeción sobrevenida depende de cómo se interprete la mención a la objeción de conciencia que figura en el artículo $30.2 \mathrm{CE}$ y de cuál sea el contenido esencial del derecho allí regulado. Porque en virtud del artículo 53.1 $\mathrm{CE}$, la ley que regule el ejercicio de dicho derecho deberá respetar su contenido esencial. Ciertamente ésta es una idea un tanto redundante, porque es obvio que una configuración infraconstitucional de los derechos fundamentales no puede ser contraria a lo que sobre ellos dispone la Constitución. ${ }^{2}$ Lo que hace la garantía expresa del contenido esencial, al fin y al cabo, es reforzar esa obviedad dogmática recordando que los derechos garantizados en la Constitución tienen en ella un contenido determinado. Es decir, el constituyente manifiesta que las menciones de derechos y libertades que incluye en la Constitución no son meras referencias lingüísticas que han de llenarse como buenamente se pueda, sino que expresan ideas concretas que, al menos en cierto nivel «esencial» o elemental, es obligatorio identificar y respetar. Con otras palabras, el constituyente adopta unas preferencias valorativas al conferir derechos y exige que su opción distributiva esté garantizada en cualquier legislación futura.

${ }^{2}$ En este sentido Ignacio de Otto sostuvo que el contenido esencial no añade ningún límite a la configuración de los derechos. Vid. I. de OTTO Y PARDO, «La regulación del ejercicio de los derechos y las libertades. La garantía de su contenido esencial en el artículo 53.1 de la Constitución», en L. MARTÍN-RETORTILLO e I. DE OTTO Y PARDO, Derechos fundamentales y Constitución, Madrid: Civitas, 1988, pp. 93-172. Tomo este análisis como un punto de referencia básico de mi exposición. Complementariamente pueden verse, entre otros muchos: M. MEDINA GUERRERO, $L a$ vinculación negativa del legislador a los derechos fundamentales, Madrid, MacGraw Hill, 1996; y A-L. MARTÍNEZ-PUJALTE, La garantía del contenido esencial de los derechos fundamentales, Madrid, Centro de Estudios Constitucionales, 1997; así como la bibliografía citada en ambos. 
Según lo dicho, lo que importa para resolver el problema constitucional de la objeción sobrevenida es saber cuál es la idea concreta que al respecto contiene la Constitución. Una vez identificada esa idea en sus términos esenciales, bastará con contrastarla con el pasaje legal discutido, sin más; en particular, sin introducir en la solución del problema consideraciones de razonabilidad política o social. Este viene a ser el planteamiento que subyace al voto particular destacado, el cual describe la concepción constitucional de la objeción de conciencia como el reconocimiento de un derecho a la exención del servicio militar obligatorio sin exclusiones temporales, ni siquiera en virtud de la situación militar del objetor.

Así las cosas, puede resultar fructífero ordenar estas ideas en correspondencia con la distinción, en boga de unos años a esta parte, entre principios y reglas. No creo preciso reproducir aquí los términos en los que se plantea esta distinción, ni el debate que ha suscitado. ${ }^{3}$ Me conformaré con aprovechar algunas de las conclusiones que en mi opinión se derivan de ese debate. Una de ellas es que entre las normas jurídicas válidas es posible distinguir unas (principios) que no identifican con nitidez sus condiciones de aplicación, de modo que no pueden resolver unívocamente los conflictos a los que son aplicables; y otras (reglas) que expresan con claridad las situaciones en que son aplicables y sus excepciones, de modo que su intervención en un conflicto es concluyente. Asociada a esa diferencia básica hay también otras, entre ellas una relativa a la precisión de la conducta ordenada: ésta es normalmente más específica en las reglas, mientras que los principios son sobre todo -como hace ver Robert Alexy- mandatos de optimización (normas que ordenan la realización de una conducta en la mayor medida posible dadas las posibilidades jurídicas y fácticas). No debería ser necesario advertir que esta diferenciación es meramente doctrinal y no responde con perfección a las complejidades de la vida jurídica. Pero es una diferenciación útil para el análisis, y en particular -sostendré- para el análisis de los derechos fundamentales. Uno de los problemas de la distinción principios/reglas es, para empezar, que no hay (apenas) reglas en el sentido de normas concluyentes. Sobre este punto me extenderé más adelante. ${ }^{4}$ Pero

${ }^{3}$ Vid. entre otros muchos: R. DWORKIN, Taking Rights Seriously, London, Duckworth, 1978; R. ALEXY, Teoría de los derechos fundamentales, trad. M. Atienza, Madrid, Centro de Estudios Constitucionales, 1989; L. PRIETO, Sobre principios y normas, Madrid, Centro de Estudios Constitucionales, 1992; M. ATIENZA y J. RUIZMANERO, Las piezas del Derecho, Barcelona, Ariel, 1996. Mi modo de entender este debate lo expongo en J. R.-TOUBES MUÑIZ, «Legal Principles and Legal Theory», Ratio Juris 10/3 (1997), pp. 267-287.

${ }^{4} \mathrm{La}$ (virtual) inexistencia de reglas jurídicas puras es, por otra parte, lo que a mi juicio permite simplificar la distinción entre principios y reglas y prescindir aquí de la categoría de principios estrictos que, en contraste con la de directrices, han introducido en los principios Manuel Atienza y Juan Ruiz Manero (Las piezas del Derecho cit., pp. 5 ss.). En mi opinión, 
esta realidad no impide que podamos usar la mencionada categoría doctrinal de regla como un modelo al cual reconducir para su estudio normas de estructura semejante, e incluso al cual adaptar reconstrucciones de normas con vistas a su utilización futura.

Para decirlo ya, en mi opinión es seguramente posible y probablemente útil reconstruir las normas constitucionales que garantizan derechos fundamentales como si fueran reglas, es decir, como si fueran normas concluyentes o -por lo que luego veremosa todas luces concluyentes. Ésta es una opinión arriesgada, porque es más habitual en la doctrina, y aparentemente más conforme con la práctica jurídica, tratar las normas constitucionales como principios, es decir como criterios de conducta más o menos difusos consistentes sobre todo en mandatos de optimización. En nuestro ejemplo, la aproximación al tratamiento constitucional de la objeción de conciencia que cabe esperar de la doctrina, simplificando el proceso, es la siguiente. En primer lugar se trata de armonizar el mandato de proteger la objeción de conciencia (art. 30.2 CE) con el mandato de defender a España (art. $30 \mathrm{CE}$ ), y acaso también con otros mandatos conexos como proteger la libertad de conciencia (art. $16 \mathrm{CE}$ ) o hacer posible que las Fuerzas Armadas cumplan su función (art. $8 \mathrm{CE}$ ). Se trata de una operación preliminar de contraste e integración de principios, la cual se podría denominar ponderación si no fuera porque este término está asociado al proceso que quiero impugnar. No tengo objeciones que plantear a esta operación, que es imprescindible, pero debe tenerse en cuenta que las normas citadas también implican reglas, de modo que los principios que se armonizan en esta fase no son todo el contenido de dichas normas, sino sólo un aspecto. En segundo lugar -continúa la doctrina común- se procede a ponderar los derechos subjetivos y los demás bienes protegidos que se suponen inscritos en tales principios. Simplificando de nuevo para nuestro caso, el derecho a la objeción de conciencia y el funcionamiento eficaz de las Fuerzas Armadas. De manera que se considera que aquel derecho está limitado por este bien, al

tales principios estrictos no son sino reglas imperfectas, reglas cuya validez depende de que salgan airosas del conflicto con otras reglas con similar autoridad. Y como el común de las reglas jurídicas reales son imperfectas en este mismo sentido, para utilizar la noción de regla pienso que debemos aplicarla flexiblemente a todas las normas que se asemejan a la noción abstracta de regla en su carácter concluyente. Así sucede con los llamados principios estrictos, que operan como razones últimas (aunque no excluyentes, dado su inevitable carácter prima facie): cfr. op. cit. p. 14. Desde otro punto de vista, entiendo que los principios estrictos vienen a ser el núcleo normativo inexcusable (una suerte de contenido esencial) de las directrices. Por eso no me parece inapropiado conservar la distinción entre principios como mandatos de optimización, por un lado, y reglas como mandatos más específicos, por otro, los cuales expresan tanto el contenido de normas ad hoc (normas regladas) como el nivel mínimo de satisfacción requerido en los principios. 
tiempo que la protección de dicho bien ha de compatibilizarse con el mayor respeto posible a aquel derecho. Es decir, el tratamiento constitucional de la objeción de conciencia se enfoca como una función de la reseñada ponderación adecuada de bienes constitucionales.

Frente a la aproximación habitual, me parece que es posible y útil un enfoque alternativo. Se trata de identificar la regla o reglas constitucionales relativas a la objeción de conciencia; es decir, la norma concluyente que la regula. Una vez contemos con esa regla basta con aplicarla a los casos donde es relevante y éstos podrán ser resueltos de modo autoritativo, sin necesidad de reproducir una y otra vez los debates sobre la extensión y los límites del derecho fundamental polémico. La principal regla buscada vendría a ser aquella (garantista) que prohíbe las conductas contrarias al contenido esencial del derecho constitucional a la objeción de conciencia, de modo que para formular la regla sería de gran ayuda saber a ciencia cierta de la existencia de dicho derecho constitucional y conocer su contenido esencial. Pero no nos es dado resolver así el problema, porque las dificultades para identificar el contenido esencial de un derecho son exactamente las mismas que las presentes para identificar la regla constitucional que garantiza ese derecho, no en vano ambas entidades son dos caras de la misma moneda. Por tanto debemos afrontar al mismo tiempo ambas pesquisas, aunque aquí enfoque la indagación hacia la formulación de reglas.

Para formular la regla constitucional sobre objeción de conciencia hay que emprender una interpretación sistemática del conjunto de la Constitución. Lo cual exige, indudablemente, poner en contacto los principios que en ella se recogen, como admití sin reparos hace un momento. Pero no procede, en cambio, bosquejar a continuación un derecho a la objeción sólo para someterlo, en cada coyuntura, a un nuevo escrutinio bajo el nombre de ponderación. En su lugar procede más bien, creo, definir el derecho de la forma más estable posible; o lo que es lo mismo, construir una regla que exprese la garantía del derecho a la objeción de conciencia contenida en la Constitución. Para hacer esto necesitaremos tener en cuenta todos los datos sustantivos relevantes: ante todo el texto de la Constitución, pero seguramente también otros materiales como el trasfondo constituyente (ideológico e histórico), el constitucionalismo comparado y, sobre todo, la jurisprudencia constitucional. No quiero decir con esto que el Tribunal Constitucional determina la forma de las reglas que es viable deducir de la Constitución -por lo pronto no puedo decirlo si quiero conservar la tesis normativa de este artículo, a favor de reconocer ya en la $\mathrm{CE}$ el derecho a la objeción sobrevenida-, pero sí que la formulación de tales reglas no puede desconocer el tratamiento jurisprudencial de los asuntos que aborde. Por decirlo de modo familiar, sólo es posible apartarse de la doctrina del TC justificando 
esta desviación. Eso es al menos lo que trato de hacer aquí al apoyarme en los votos particulares partidarios de declarar inconstitucional la exclusión legal de la objeción sobrevenida.

Tomemos entonces la Constitución en su conjunto y tratemos de desentrañar cuál es el contenido reglado de la protección de la objeción de conciencia que tiene aplicación al problema de la sobrevenida. El texto más relevante dice así: «La ley (...) regulará, con las debidas garantías, la objeción de conciencia, así como las demás causas de exención del servicio militar obligatorio,...» (art. 30.2 CE). De este párrafo se desprende la presencia de una primera regla del tenor (digamos): «Es obligatorio para el legislador regular la objeción de conciencia como una causa de exención al servicio militar». Del significado garantista de la Constitución se desprende, a su vez, que esa regla tiene el sentido de proteger a quienes por razones de conciencia pretenden eximirse del servicio militar, y no sólo -como cabría malinterpretar con una lectura excesivamente literal- de asegurar que la objeción está regulada, sea en la dirección que sea. Por tanto, la regla de partida es más bien: «Es obligatorio para el legislador proteger la objeción de conciencia...». Es decir, no sería acorde con la Constitución una legislación que regulase la objeción prohibiéndola. En este sentido cabe hablar, como de hecho se hace normalmente, de un derecho constitucional a la objeción de conciencia. Este derecho es el correlato de la regla que ordena proteger la objeción. Por eso podemos formular la regla anterior todavía de otro modo: «Es obligatorio para el legislador respetar el derecho a la objeción de conciencia». Decimos «respetar» en este contexto porque se trata de un derecho constitucional previo a la tarea legislativa de regularlo, no porque sea un derecho natural previo a cualquier positivación.

Ahora bien, no podemos llamar a las formulaciones anteriores reglas si no precisamos qué es la objeción de conciencia al servicio militar. Porque la regla sugerida, si es efectivamente una regla, obliga de forma (a todas luces) concluyente a que el legislador realice una conducta mas bien específica. Y aquellos mandatos sólo pueden ser específicos si no hay duda acerca de qué ha de entenderse por objeción de conciencia al servicio militar. Esta identificación indubitable de la conducta ordenada puede haberse llevado a cabo explícitamente, como corresponde al concepto abstracto de regla, pero tiene claramente un componente implícito incorporado. Es decir, para formular una regla de derecho fundamental hay que atender a lo que sobre éste se dice en la Constitución tanto explícita como implícitamente. Pues bien, así las cosas, la fijación del significado constitucional de la conducta ordenada pudiera representar un problema para la formulación de reglas constitucionales respecto de otros derechos, pero no me parece que plantee mayores dificultades en este caso. En efecto, no está en discusión lo que significa 
objeción de conciencia al servicio militar. Por ejemplo, sabemos que no se refiere a la que pueden plantear quienes no han sido llamados a filas (v.gr. mujeres), y por tanto entendemos que la Constitución no obliga al legislador a regular esa objeción. Entonces, dado este entendimiento indiscutido, la formulación anterior de la regla que enunciaba la obligación por parte del legislador de respetar el derecho a objetar no incluye la obligación de respetar ese derecho también en quienes no han sido llamados a filas. Y podemos continuar desarrollando excepciones implícitas: no protege a los objetores de conveniencia (esto es, a los que no son de conciencia), no protege a los objetores que están liberados del servicio militar, etc. Es cierto que una auténtica regla (esto es, aquella que se ajusta al concepto abstracto de regla) tiene sus excepciones explícitamente reconocibles, pero en este caso lo que llamo excepciones implícitas no son sino restricciones perfectamente previsibles originadas en la única interpretación aceptable de los términos empleados en la regla. Por regresar al ejemplo anterior, no es imaginable que se discuta en serio el carácter concluyente de las reglas anteriores con el argumento de que es dudoso si el legislador debe o no regular (protegiendo) el derecho a objetar de las mujeres no llamadas a filas.

Llegamos así a la clave de nuestro problema: ¿es, o puede ser, la objeción sobrevenida una de esas excepciones implícitas? Antes de ensayar una respuesta, repasemos por qué ésa es efectivamente la clave del problema. El sentido de aplicar una teoría de las reglas al análisis de los derechos fundamentales es reforzar estos derechos frente a consideraciones de signo opuesto carentes de igual jerarquía constitucional. Una vez identificada la regla constitucional que garantiza cierto derecho subjetivo, éste ha de ser respetado, en armonía con los demás derechos, incluso aunque haya razones de peso para postergarlo. La causa es que tales razones no pueden tener mayor peso que las razones (constitucionales) para respetar el derecho, ya que de otro modo habrían sido tenidas en cuenta como excepciones en la formulación de la regla. Porque la formulación de una regla, como se dijo, exige tener presentes todas las excepciones constitucionalmente legítimas al mandato que expresa. Tales excepciones pueden o bien consignarse expresamente (digamos: «Está prohibido impedir la petición colectiva; excepto a militares») o bien pertenecer de suyo, e implícitamente, al significado de la regla. En este último caso sería posible en teoría, con un gran esfuerzo, hacer expresas las excepciones (digamos: «Está prohibido impedir el matrimonio al hombre y la mujer» se convertiría en «Está prohibido...; excepto cuando se contraríen las formas legales, se pretenda en edad legalmente improcedente...»). Los aspectos conflictivos se incorporan con más dificultad a la regla, con ayuda de la interpretación doctrinal y jurisprudencial. En nuestro caso, para identificar el contenido de la regla constitucional que 
protege (el derecho a) la objeción de conciencia es necesario determinar si aquella regla contempla como excepción implícita -pues está claro que no lo es explícita- una de estas dos: a) que la exención del servicio militar se pretenda estando el objetor en filas (excepción constitucional inmediata); o $b$ ) que el legislador regule la objeción de forma que no pueda ejercerse en filas (excepción legal con legitimación o fundamento constitucional). Si determinamos que no es así, que la regla constitucional no contiene ninguna de esas excepciones, entonces impedir la objeción sobrevenida será contrario a dicha regla -es decir, inconstitucional- aunque esté justificado por razones administrativas o militares. Por eso la clave de nuestro problema es resolver si pretenderse objetor en filas es una excepción implícita en la garantía constitucional (reglada) de la objeción de conciencia.

En mi opinión debe afirmarse que la regulación constitucional que garantiza la exención al servicio militar por objeción de conciencia no exceptúa de ninguna manera su pretensión en filas. No hay justificación constitucional suficiente, ni sustantiva ni jerárquicamente, para introducir en la mención garantista de la objeción de conciencia que hace el artículo 30.2 CE una limitación temporal como la discutida. Es posible que haya razones (de operatividad, de conveniencia política, de economía) para prohibir la objeción sobrevenida; pero no son razones que en la Constitución tengan entidad bastante para invalidar la protección del derecho a eximirse del servicio militar por objeción de conciencia que con claridad, y sin salvedades, contiene el art. 30.2 CE. La autorización al legislador para regular «con las debidas garantías» ese derecho no puede entenderse, so pena de vaciar de contenido la norma constitucional, como la introducción de una excepción implícita según la cual la obligación de proteger el derecho desaparece cuando el legislador así lo estima oportuno. Por el contrario, la obligación de proteger el citado derecho es una imposición constitucional que el legislador no puede desatender en ningún momento, sino que se ha de limitar a regularla. Si hemos de extraer de la Constitución una regla respecto a la objeción sobrevenida, ésa es que el legislador está obligado a respetarla en cuanto causa de exención del servicio militar obligatorio.

Hay una predecible objeción a la tesis expuesta. He sostenido que hay supuestos en los que es dudoso si cierta restricción al derecho ocupa en la formulación de la regla constitucional el lugar de una excepción (implícita), y que en tales casos conflictivos conviene iluminar la interpretación sistemática del conjunto de la Constitución con materiales como, destacadamente, la jurisprudencia constitucional. He aquí que tenemos entre manos un caso conflictivo (la objeción sobrevenida) y una solución jurisprudencial. Por tanto sería de esperar que construyésemos la regla constitucional sobre la objeción sobrevenida teniendo en cuenta la argumentación del 
TC (y no, por cierto, la de los votos particulares disidentes). En particular, parecería que una comprensión adecuada de la Constitución, a la luz de la doctrina actual del TC, debe llevar a formular una regla del siguiente tenor: «Es obligatorio para el legislador proteger el derecho a la objeción de conciencia al servicio militar; excepto... cuando el legislador, tras ponderar todos los bienes jurídicos protegibles, introduce una restricción no excesiva». O bien, más en concreto, «... excepto... cuando el objetor está en filas y el legislador, tras ponderar todos los bienes jurídicos protegibles, entiende que debe impedirse la objeción en filas». No dispongo de una réplica contundente a esta objeción. La única respuesta que puedo ofrecer es que la interpretación procedente del TC es en este caso errónea, y que con ella deben ser rechazadas las formulaciones de reglas que se apoyan en dicha interpretación. Lo cierto es que no me parece descabellado sostener que se trata de una interpretación claramente errónea, a juzgar por la reacción doctrinal que ha provocado. A mi juicio, como se desprende de lo dicho, no puede ser correcta una lectura del art. 30.2 CE según la cual el legislador puede privar a un objetor de conciencia de la posibilidad de eximirse del servicio militar siempre que así lo crea oportuno tras ponderar todos los bienes jurídicos protegibles, y siempre que la restricción no sea excesiva en opinión del TC. Porque esta lectura puede vaciar de contenido la garantía constitucional del derecho a la objeción de conciencia, al dejarla a merced de lo que el TC considere razonable o excesivo como restricción. Los derechos protegidos por la Constitución, correctamente entendidos, tienen un sentido propio -al menos en un nivel elemental- cuya eficacia no debería estar expuesta a los juicios de conveniencia coyunturales que de ellos haga un Tribunal.

Por otra parte, y dado que la doctrina del TC puede cambiar, y de hecho cambia, la identificación de reglas constitucionales no debe someterse ciegamente a las interpretaciones del TC. Por eso aunque la jurisprudencia constitucional debe ser tenida en cuenta en esa identificación de reglas, no es necesario ni conveniente adaptarse a ella. Máxime cuando, como ocurre en nuestro ejemplo, está amplia y sólidamente contestada. Tal vez deba hablarse de dos tipos de reglas de derechos fundamentales derivadas de la Constitución. Unas formulan los derechos tal como son aplicables a los ciudadanos, y vienen definidas por la jurisprudencia del TC y otras intervenciones autorizadas (legislación y jurisdicción ordinaria). Otras formulan los derechos tal como se desprenden de la propia Constitución, y vienen definidos por la lectura informada de la Constitución y de sus interpretaciones competentes, que no es patrimonio exclusivo del TC. Este segundo tipo de reglas expresa cómo deberían ser entendidos los derechos fundamentales por el TC y sus otros intérpretes autorizados. En cambio, es el primer tipo el que expresa cómo deben ser entendidos por los órganos judiciales, los 
cuales han de atenerse a las interpretaciones autorizadas aunque sean defectuosas desde un punto de vista doctrinal.

\section{Carácter concluyente de las normas constitucionales}

Una vez examinado, siquiera someramente, el caso particular de la objeción sobrevenida a la luz de una teoría de las reglas de derechos constitucionales, me gustaría acabar tratando un punto que he venido posponiendo: la pertinencia de atribuir a ciertas normas (reglas) un carácter concluyente. Éste es en realidad un punto previo a toda la construcción de los derechos fundamentales como reglas, pero no creo que sea decisivo para contrastar su validez. No lo es, porque en todo momento he asumido que la noción de regla es una categoría de análisis teórico, un modelo, y que en la práctica no existen (apenas) normas jurídicas que sean auténticas reglas concluyentes, sino a lo sumo sólo normas a todas luces concluyentes o normas que pueden ser reconstruidas ad hoc como reglas concluyentes. Veremos ahora por qué, pero en todo caso esta matización explica que pueda haber pospuesto este punto hasta ahora, y que ahora lo trate casi a modo de apéndice.

Todas las normas jurídicas tienen fuerza decisoria sólo prima facie, pues son aplicables sólo si no lo impide otra norma de mayor peso. En esa medida las normas jurídicas no son concluyentes. Pero hay normas de las cuales cabe esperar su aplicación en todos los supuestos, porque no es previsible que entren en conflicto con una norma superior. En esa medida hay normas que son a todas luces concluyentes. Pienso, por ejemplo, en la norma que expresa el artículo $18 \mathrm{CE}$ : «Los españoles son mayores de edad a los 18 años». Es una norma prima facie como todas, pero no se me ocurre en qué condiciones podría postergarse su aplicación justificadamente. Por otra parte, es posible tomar las normas aplicadas a un caso y reconstruirlas en forma de reglas concluyentes (decisoras) para ese caso. Con la oportuna autoridad en la formulación, tales reglas pueden convertirse en normas concluyentes también para casos futuros semejantes. Tenemos por tanto al menos dos sentidos en los que cabe hablar con propiedad de reglas, pese a tratarse siempre de normas sólo prima facie aplicables: a) normas previsiblemente (a todas luces) concluyentes; y b) normas retrospectivamente concluyentes. Todo esto teniendo en cuenta, además, que en puridad una regla es válida sólo si es aplicable. Porque el hecho de que las reglas contemplen todas sus excepciones, como corresponde a su naturaleza, implica que una regla sólo puede ser postergada en virtud de una excepción imprevista si no es una regla válida. En este sentido, de las reglas debe decirse que en la práctica sólo son válidas prima facie. Porque puede aparecer una circunstancia imprevista que demuestre que la regla es inaplicable tal y como había sido previamente formulada, dado que debe ser postergada en favor de otra norma. 
Esta circunstancia invalidante ha de formar parte de la formulación de la regla para que ésta sea de nuevo válida prima facie.

Otra forma de enfrentarse al problema anterior es la ensayada por Neil MacCormick en un interesante trabajo sobre la presencia de «inconclusividad»-defeasibility, término que no sé traducir de mejor manera- en el Derecho y en la Lógica. ${ }^{5}$ MacCormick observa que junto a las ocasiones en que una regla jurídica somete expresamente a una excepción o cláusula la producción de un efecto que de otra forma debería producirse, coexiste una posibilidad de excepción o «inconclusividad» implícita. Porque según él, es siempre correcto entender las formulaciones expresas de las reglas constitutivas de las instituciones jurídicas «como si sólo dispusiesen condiciones "normalmente necesarias y presumiblemente suficientes" para las ordenaciones que regulan», de modo que son posibles excepciones implícitas. ${ }^{6}$ Ahora bien, seguir aquí a MacCormick no significa desvirtuar la interpretación de los derechos fundamentales como reglas concluyentes, según creo. Porque él propone atribuir la inconclusividad no a los verdaderos derechos, sino a las pretensiones de derechos que toman erróneamente las condiciones satisfechas en el caso como si fueran suficientes para adquirir el derecho. En tales supuestos -nos dice- no es que el derecho fuese desestimado por efecto de otros elementos (inconclusividad), sino que simplemente no existía. «De modo que después de todo no es el concepto lo que no es concluyente, sino alguna formulación de las condiciones para manifestar el concepto en supuestos dados, o alguna afirmación, adscripción o pretensión basada en una cierta comprensión de esas condiciones». ${ }^{7}$

El referido planteamiento de MacCormick, que merecería ser repasado por extenso, me reafirma en la opinión de que los derechos fundamentales pueden, y tal vez deban, ser concebidos como reglas concluyentes, aunque en la práctica jurídica éstas no existan, dadas las limitaciones técnicas para la formulación de enunciados normativos. ${ }^{8}$ Apoyándose en la pragmática procesal de la carga de la prueba, MacCormick sitúa la clave en no confundir

${ }^{5}$ N. MacCORMICK, «Defeasibility in Law and Logic», en Z. BANKOWSI et al. (eds.), Informatics and the Foundations of Legal Reasoning, Dordrecht, Kluwer, 1995, pp. 99-117.

${ }^{6}$ MacCORMICK, «Defeasibility...»cit., p. 100.

${ }^{7}$ MacCORMICK, «Defeasibility...» cit., p. 102.

${ }^{8}$ Escribe MacCormick, «Defeasibility...» cit., p. 103: «Notoriamente, sería extremadamente difícil, quizás imposible, y sin duda el enemigo de cualquier clase de claridad o cognoscibilidad en el Derecho, intentar una formulación de toda precondición de validez concebible en cada enunciado de cada regla» (...) «El enunciado general del derecho es adecuado si estipula lo necesario y suficiente para la determinación del derecho en el común de los casos, sujeta a cualquier excepción o cláusula expresa respecto a los factores invalidantes recurrentes y fácilmente previsibles (o bien documentados doctrinalmente o establecidos jurisprudencialmente). 
los requisitos intrínsecos a las normas con las excepciones extraordinarias con que quepa oponer su aplicación (y que en teoría deberían estar igualmente expresadas en la regla so pena de invalidez). Según sugiere, «debe tenerse en cuenta de forma cabal la diferencia entre lo que es razonable formular como las condiciones normalmente necesarias y presumiblemente suficientes de alguna titularidad jurídica, y las condiciones más bien excepcionales o inusuales que otra parte interesada puede ser capaz de aducir como objeciones a otorgar finalmente la titularidad». ${ }^{9}$ Concluyendo, cabe pensar que la carencia de reglas completas en la Constitución - $y$ en general en el conjunto del ordenamiento jurídico- no desautoriza la tarea de reconstruir las supuestas reglas de derechos fundamentales. Pues aquella carencia, que es una consecuencia razonable del hecho de que ciertas excepciones a la atribución de derechos son inauditas, puede ser hipotéticamente corregida una vez que en la práctica jurídica la parte que se opone al reconocimiento del derecho actualiza y alega las excepciones implícitas.

Completaré este punto ensayando una aplicación, tal vez apresurada, de la distinción entre requisitos razonablemente previsibles y excepciones inusuales al derecho a la objeción sobrevenida. Cabe pensar que el legislador ha visto su competencia para impedir el ejercicio en filas de la objeción como una condición negativa o requisito intrínseco de la atribución constitucional de un derecho a la objeción de conciencia. Dicho de otro modo, una interpretación favorable al legislador sería que entre los requisitos intrínsecos de la titularidad del derecho constitucional a la objeción de conciencia figuran las limitaciones temporales que para su ejercicio pueda introducir la ley de desarrollo. Esta interpretación me parece inadecuada, porque implica asumir, de forma inverosímil, que la ausencia de limitación temporal legal es una condición normalmente necesaria de la titularidad del derecho a la objeción de conciencia, cuando la Constitución no dice nada al respecto. Una segunda interpretación, que presumiblemente cabe atribuir al Tribunal Constitucional, es que la limitación temporal legal es una excepción imprevista en la formulación expresa, pero legítima por estar implícita en el contexto constitucional. Esto explicaría la exclusión de la objeción de conciencia sobrevenida pese a no estar exceptuada en el artículo 30.2 CE. Sin embargo creo que no es una interpretación convincente, porque implica considerar la limitación temporal legal como una opción razonablemente imprevisible en el momento constituyente. Queda entonces una tercera interpretación: el límite temporal legal es una excepción imprevista pero previsible, y por tanto ilegítima desde el punto de vista constitucional (no es una excepción implícita ni mucho menos un requisito intrínseco).

\footnotetext{
${ }^{9}$ MacCORMICK, «Defeasibility...» cit., p. 106.
} 
DOXA 21-I (1998) 